\title{
Dendritic fibromyxolipoma: A case report
}

\author{
HONGYUN LIU ${ }^{1 *}$, SHUMIN HEI $^{2 *}$, JIGANG WANG $^{3}$, QILIANG ZHANG ${ }^{4}$, XINJUAN YU $^{5}$ and HUACHEN ${ }^{*}$ \\ ${ }^{1}$ Department of Pathology, Qingdao Municipal Hospital; ${ }^{2}$ Department of Pathology, School of Basic Medicine, \\ Qingdao University, Qingdao, Shandong 266071; ${ }^{3}$ Department of Pathology, The Affiliated Hospital of Qingdao University, \\ Qingdao, Shandong 266003; Departments of ${ }^{4}$ Sports Medicine and ${ }^{5}$ Central Laboratories, \\ Qingdao Municipal Hospital, Qingdao, Shandong 266071, P.R. China
}

Received November 20, 2019; Accepted October 7, 2020

DOI: $10.3892 / \mathrm{mco} .2020 .2169$

\begin{abstract}
Dendritic fibromyxolipoma (DFML) is a rare variant of spindle cell lipoma. It is characterized by extensive myxoid change and the presence of stellate cells with dendritic processes. The present study reports three cases of DFML that arose from the limbs and thoracic cavity. Pathologically, the tumor was composed of mature adipocytes admixing with patch spindle cells in a myxoid stroma. The cell atypia was not apparent and mitotic figures were rare. Immunohistochemistry revealed that the spindle cells were strongly positive for CD34. The three patients demonstrated no significant issues during a two-year's follow-up without evidence of recurrence and metastasis. The current study additionally reviewed all reported DFML cases in the PubMed database and Chinese journals.
\end{abstract}

\section{Introduction}

Dendritic fibromyxolipoma (DFML) is a rare benign tumor that was first reported by Suster et al in 1998 (1). It consists of a mixture of small spindles to stellate cells and several mature fat cells. The stellate cells were embedded in an abundant myxoid stroma with strands of ropey collagen bundles. It shares similar morphologic features to other myxoid mesenchymal tumors, such as myxoid liposarcoma (MLS) and solitary fibrous tumor (SFT). In most reports, it is considered as a special variant of spindle cell lipoma (2). It is typically

Correspondence to: Dr Hua Chen, Department of Pathology, Qingdao Municipal Hospital, 5 Donghai Middle Road, Qingdao, Shandong 266071, P.R. China

E-mail: chenhua62@163.com

${ }^{*}$ Contributed equally

Abbreviations: DFML, dendritic fibromyxolipoma; MRI, magnetic resonance imaging; CT, computed tomography; FISH, fluorescence in situ hybridization; MLS, myxoid liposarcoma; MFS, myxofibrosarcoma; SFT, solitary fibrous tumor; LGFMS, low-grade fibrous myxoid sarcoma

Key words: dendritic fibromyxolipoma, spindle cell lipoma, immunohistochemistry present in the older age population with a male preponderance. Most of these tumors occurred in head and neck, chest wall, shoulder and back, and a few were located in limbs, including toes. They are often located in superficial fascia and occasionally in muscle (2). To the best of our knowledge, only 59 cases of DFML were reported and cited in PubMed and Chinese journals. In this study, we have described three DFML cases that were located in the limbs and thoracic cavity. Written informed consents have been obtained from these three patients.

\section{Case presentation}

Case 1. The patient was a 50-year-old male who presented with a painless right upper arm tumor mass for six years. In August 2012, he was admitted to Qingdao Municipal Hospital for the first time. Recently, the tumor was gradually growing. No other mass was found in other locations. The magnetic resonance imaging (MRI) showed a well-defined tumor mass measuring 79×46×100 mm in the right upper arm. It showed a mixed-signal intensity on both $\mathrm{T} 1$ and fat-suppression weighted imaging (Fig. 1A). The tumor was completely resected. Histopathologic evaluation showed that the tumor was composed of mature adipocytes with sparse slender spindle cells (Fig. 1B). The cellular atypia was not apparent. Strands of ropey collagen bundles within the myxoid background were noted (Fig. 1C). Immunohistochemical staining showed that the spindle cells were strongly positive for CD34 (Fig. 1D), but negative for CD99 and BCL-2. A diagnosis of DMFL was suggested. The patient was uneventful during a 12-month's follow-up without evidence of recurrence.

Case 2. The patient was a 33-year-old male. He was presented with a gradually growing right thigh mass for three years. In March 2014, he was admitted to Qingdao Municipal Hospital for the first time. It measured $3 \times 3 \mathrm{~cm}$, and it did not cause any local discomfort. The ultrasound revealed a subcutaneous well-defined hyperechoic mass, which suggested a lipoma (Fig. 2A). It was resected completely. Grossly, the tumor was lobulated with an intact capsule. The cut surface was yellowish and soft. Histopathologically, the tumor was composed of mature adipocytes and sparse spindle cells with a myxoid background (Fig. 2B and C). The tumor cells were positive for CD34 (Fig. 2D) and negative for CD99 and BCL-2. 

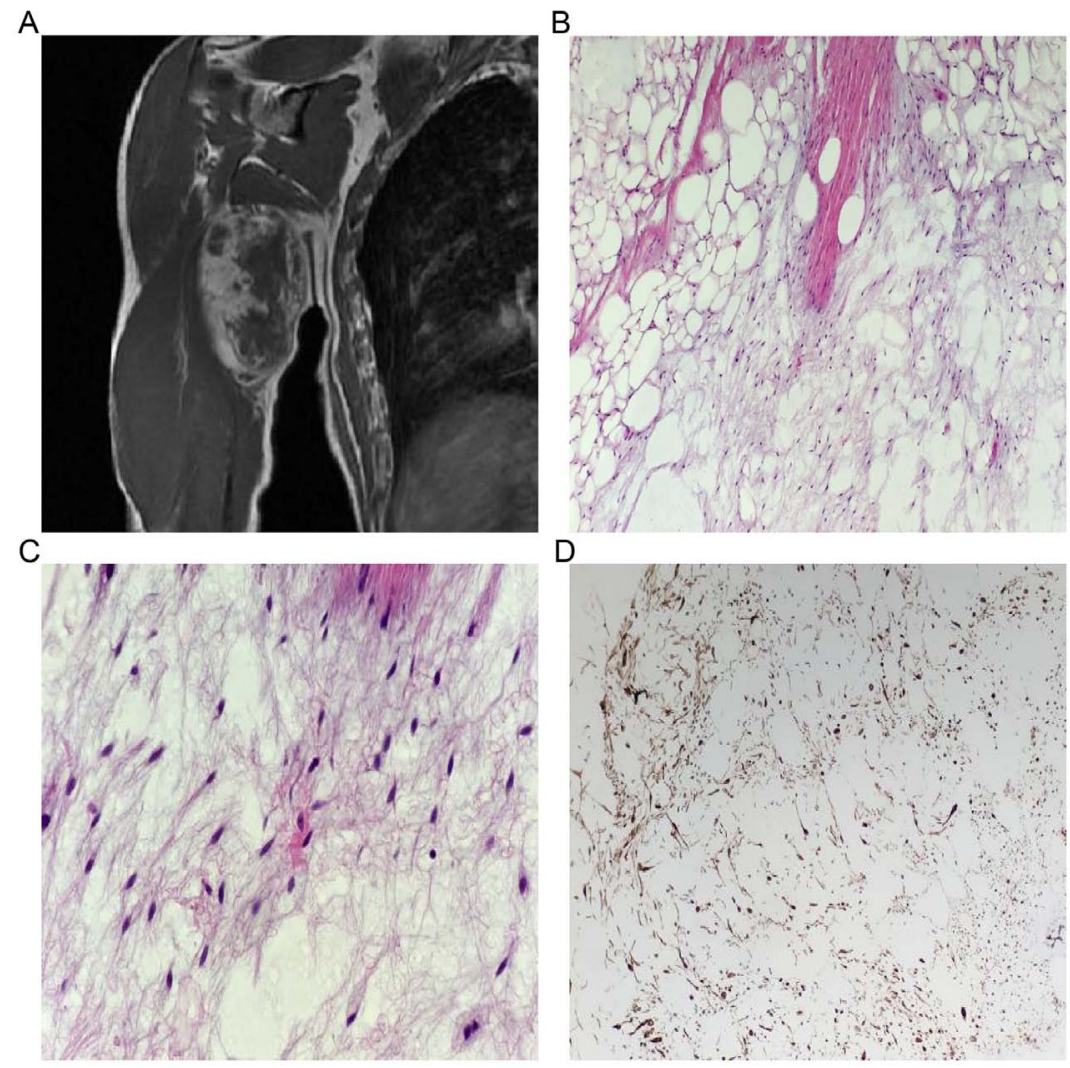

Figure 1. Case 1. (A) MRI revealing a homogeneous tumor mass in the right arm. (B) The tumor was composed of adipocytes and sparse slender spindle cells in a myxoid background (hematoxylin and eosin staining; magnification, x100). (C) Red collagen bundles were apparent under high power (hematoxylin and eosin staining; magnification, x400). (D) Immunohistochemistry staining revealed that the spindle cells were positive for CD34 (magnification, x100).
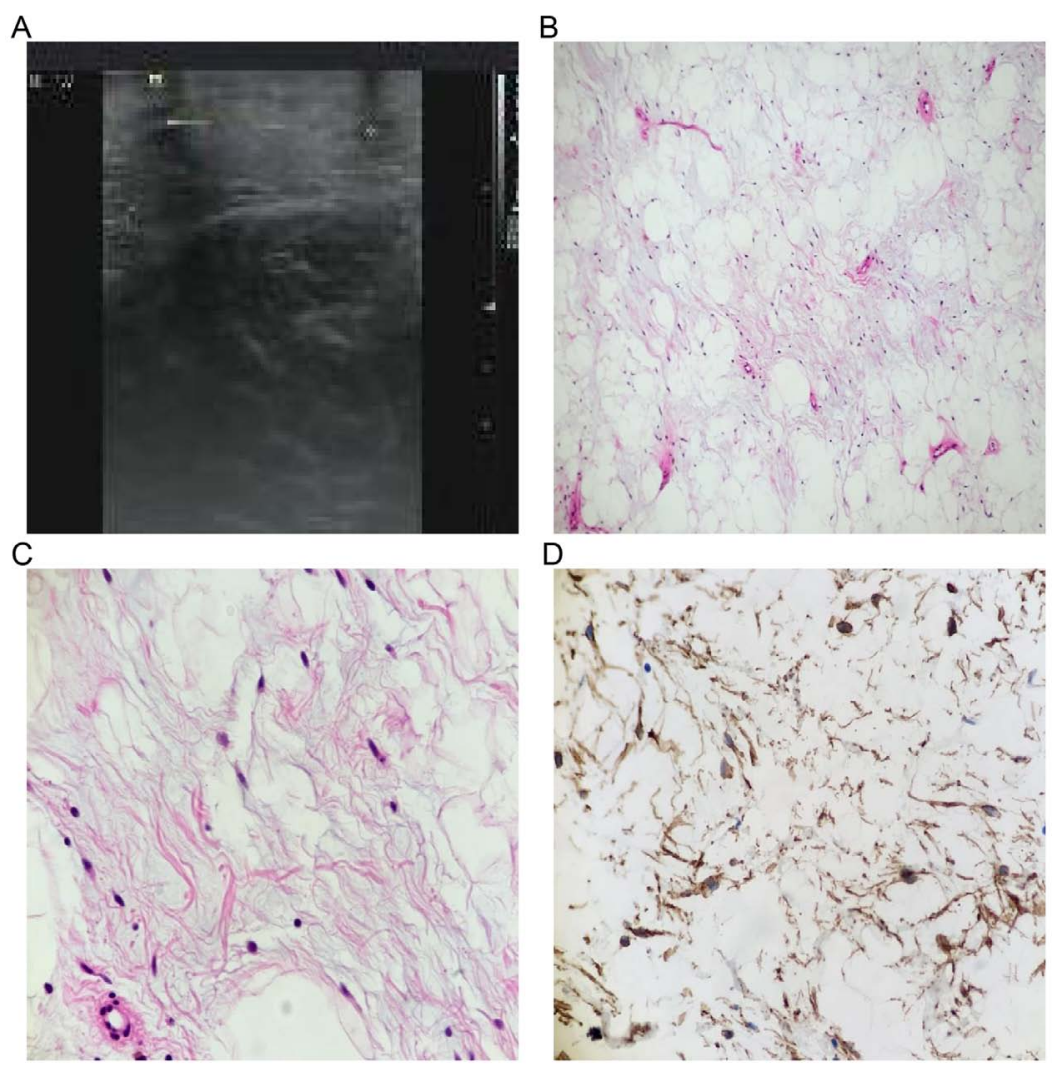

Figure 2. Case 2. (A) The tumor was composed of adipocytes in a myxoid background (hematoxylin and eosin staining; magnification, x100). (B) Slender spindle cells and red collagen bundles were observed under high power (hematoxylin and eosin staining; magnification, x400). (C) Red collagen bundles were apparent under high power (hematoxylin and eosin staining; magnification, x400). (D) Immunohistochemistry staining revealed that the spindle cells were positive for CD34 (magnification, x100). 
A

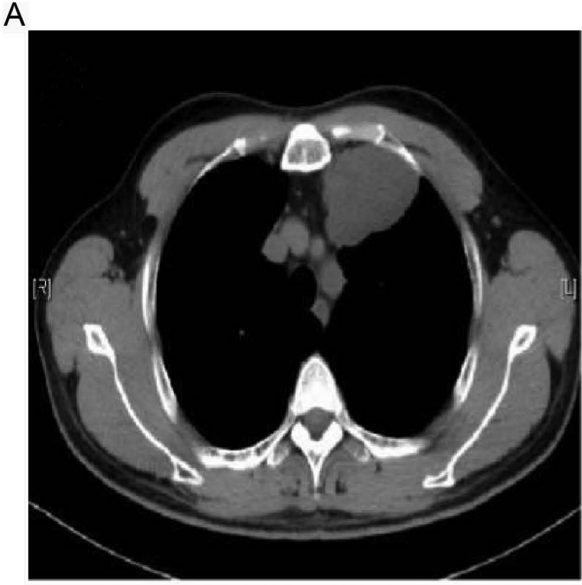

C

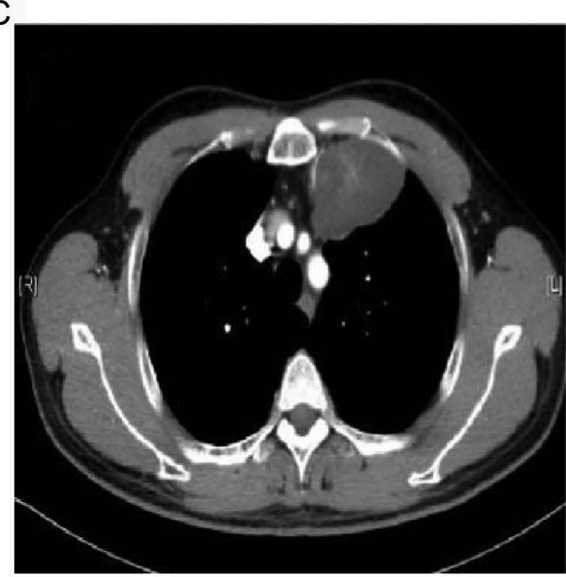

B
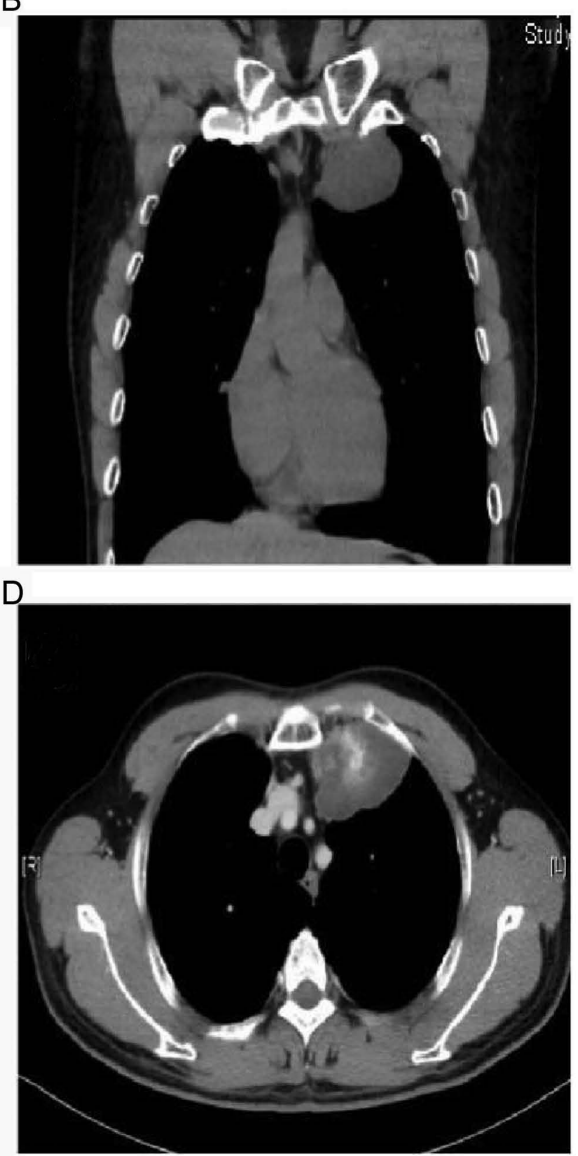

Figure 3. Case 3. (A and B) Radiological features of thoracic dendritic fibromyxolipoma on CT imaging. CT demonstrated a homogenous low-density shadow in the left thoracic cavity attaching to the anterior chest wall. It measured 43x60x36 mm with a well-defined boundary and was heterogeneously enhanced. The tumor center was enhanced more markedly in the (D) venous phase than the (C) arterial phase.

Case 3. The patient was a 48-year-old male who presented with a left thoracic tumor mass. He appeared asymptomatic, and the medical history was unremarkable. In July 2015, he was admitted to Qingdao Municipal Hospital for the first time. The tumor was incidentally observed during a routine physical examination. No other mass was found in other locations. The computed tomography (CT) showed a homogenous low-density mass in the left thoracic cavity beside the mediastinum. It measured $43 \times 60 \times 36 \mathrm{~mm}$ and had a well-defined boundary (Fig. 3A and B). The tumor center was heterogeneously enhanced, indicating the presence of blood vessels. The tumor center was enhanced more obviously in the venous phase (Fig. 3D) than the arterial phase (Fig. 3C). Considering the tumor location, a pleural SFT was suggested. In addition, a fine needle biopsy was performed, but as no adipocytes were observed, a pathologic diagnosis of myxoid subtype of SFT was made. The tumor was completely resected by video-assisted thoracic surgery. Histopathologic evaluation showed that the tumor predominantly comprised slender spindle cells embedded in an abundant myxoid stroma with strands of ropey collagen bundles (Fig. 4A and B). The cellular atypia was not apparent. Red collagen bundles were apparent under high power (Fig. 4C). Immunohistochemical staining showed that the spindle cells were strongly positive for vimentin and CD34 (Fig. 4D), but negative for BCL-2 (Fig. 4E), CD99, STAT6, S100, SMA and Desmin. The Ki-67 index was $<1 \%$.
Focal mature adipocytes were present within the myxoid background. In addition, a prominent delicate, arborizing vascular pattern was observed in some areas, which was similar to a MLS. However, the fluorescence in situ hybridization (FISH) analysis with the DDIT3 break apart probe (ZytoLight; cat. no. Z-2100-200) showed negative DDIT3 rearrangement (Fig. 4F). Therefore, a pathologic diagnosis of DFML was rendered. The patient was uneventful during a follow-up of 15 months without evidence of recurrence and metastasis.

\section{Discussion}

A literature search was performed in Pubmed, CNKI and Wanfang database to identify eligible studies published prior to October 9, 2019. Search terms were 'dendritic fibromyxolipoma' or 'DFML'. The inclusion criteria was: case report or case series on patients with DFML. The exclusion criteria was: articles that were reviews, comments, news, letters and that did not meet the inclusion criteria were excluded. Articles not in the English or Chinese language were also excluded. 20 studies were eligible involving 59 patients with DFML, including 48 males and 11 females (Table I).

DFML is an uncommon benign tumor that was initially described by Suster et al in 1998. A total of 12 cases were introduced in their report (1). Since then, a total of 47 additional cases have been reported and cited in PubMed and Chinese 
A

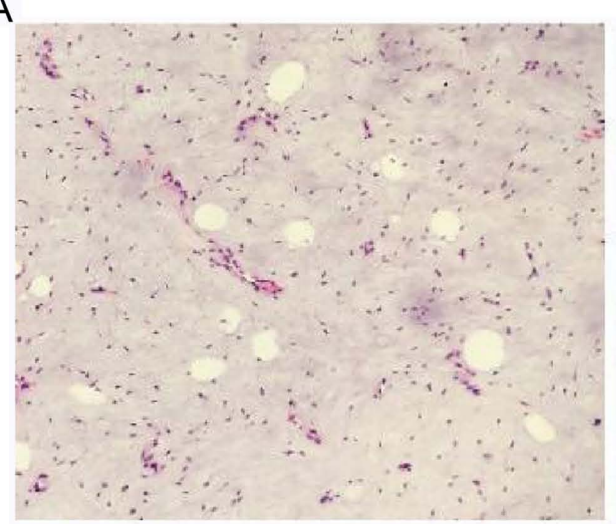

C

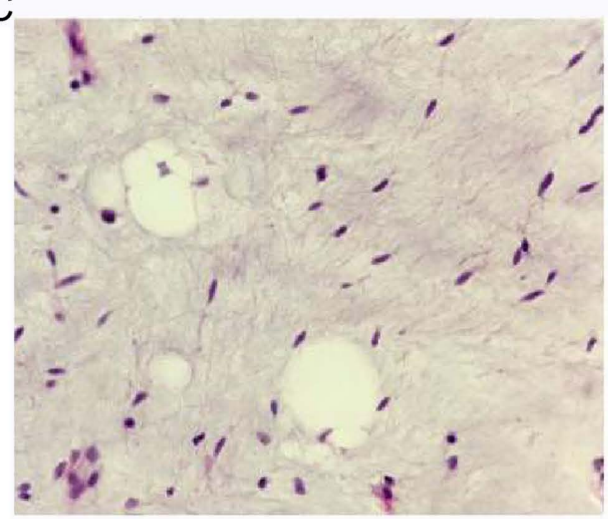

E

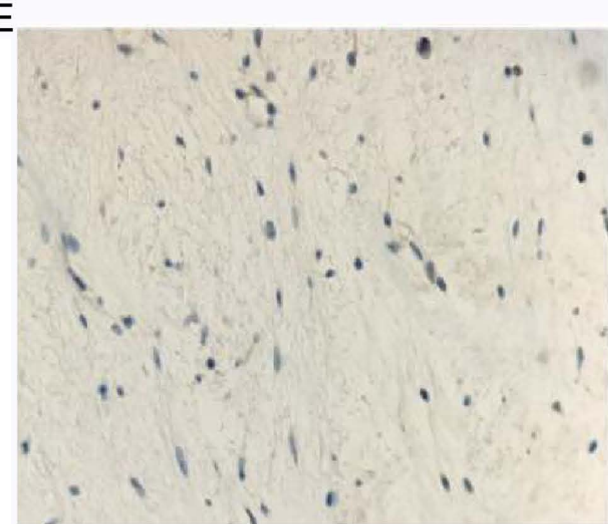

B
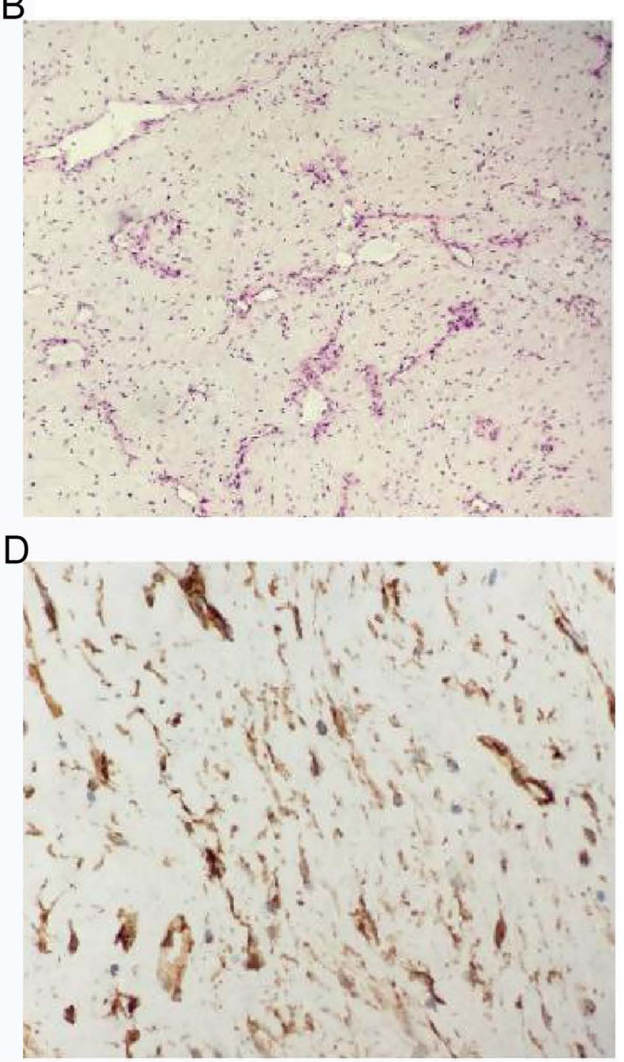

$\mathrm{F}$

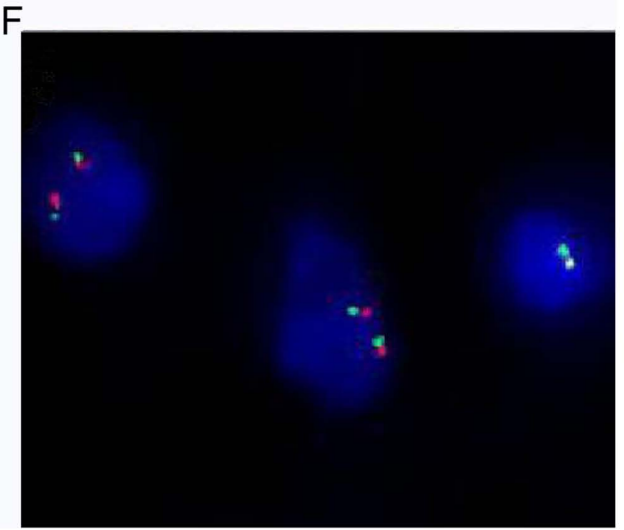

Figure 4. Case 3. Pathological features of thoracic dendritic fibromyxolipoma. (A and B) The tumor was composed of sparse spindle cells in a myxoid background. (A) Focal adipocytes and (B) delicate, arborizing blood vessels were abundant in some areas (hematoxylin and eosin staining; magnification, $\mathrm{x} 100$ ). (C) Red collagen bundles were apparent under high power (hematoxylin and eosin staining; magnification, x400). Immunohistochemistry staining revealed that spindle cells were (D) positive for CD34 (magnification, x100), but (E) negative for BCL-2 (magnification, x100). (F) Fluorescence in situ hybridization detection for DNA damage-inducible transcript 3 break apart was negative.

journals (Table I) (1-20). Although its incidence is relatively low, DFML can occur in almost all parts of the body, including the left inguinal region (15), hypopharynx (16), infraclavicular region (19), and other uncommon parts. The tumor develops primarily in the sub-cutis or muscular fascia. Among the 62 reported cases (including the current three cases), the age of patients ranges from 24 to 81 years with a male/female ratio of $51 / 11$. The tumor size ranges from 1 to $24 \mathrm{~cm}$, with an average of $8.2 \mathrm{~cm}$. Gradually growing up mass without symptoms is the most common clinical manifestation. The medical history ranged from 1 month to 13 years. When the tumor is superficial, it often manifests as a painless tumor mass for several years. To the best of our knowledge, no more than 10 cases of DFML of extremities have been reported. The clinical presentations and imaging features are rather non-specific, and the definite diagnosis relies on the histopathology. The differential diagnosis includes other myxoid mesenchymal tumors, for instance, MLS and SFT. When the blood vessels are abundant, and 'chicken-wire' like, or the fat component is not apparent, a diagnosis is rather difficult.

It has been reported that the $13 \mathrm{q} 14.3$ deletion, the hall marker of spindle cell lipoma, was detected in DFML. Thus, DFML is considered as a myxoid variant of spindle cell lipoma (2). It is mainly composed of mild spindle cells and unequal amounts of mature adipocytes. The spindle cells are small and deeply stained, without obvious atypia. The cytoplasm has long and narrow protrusions, which are dendritic. The mitotic figures are rare. According to a report, the bland spindle cells were 


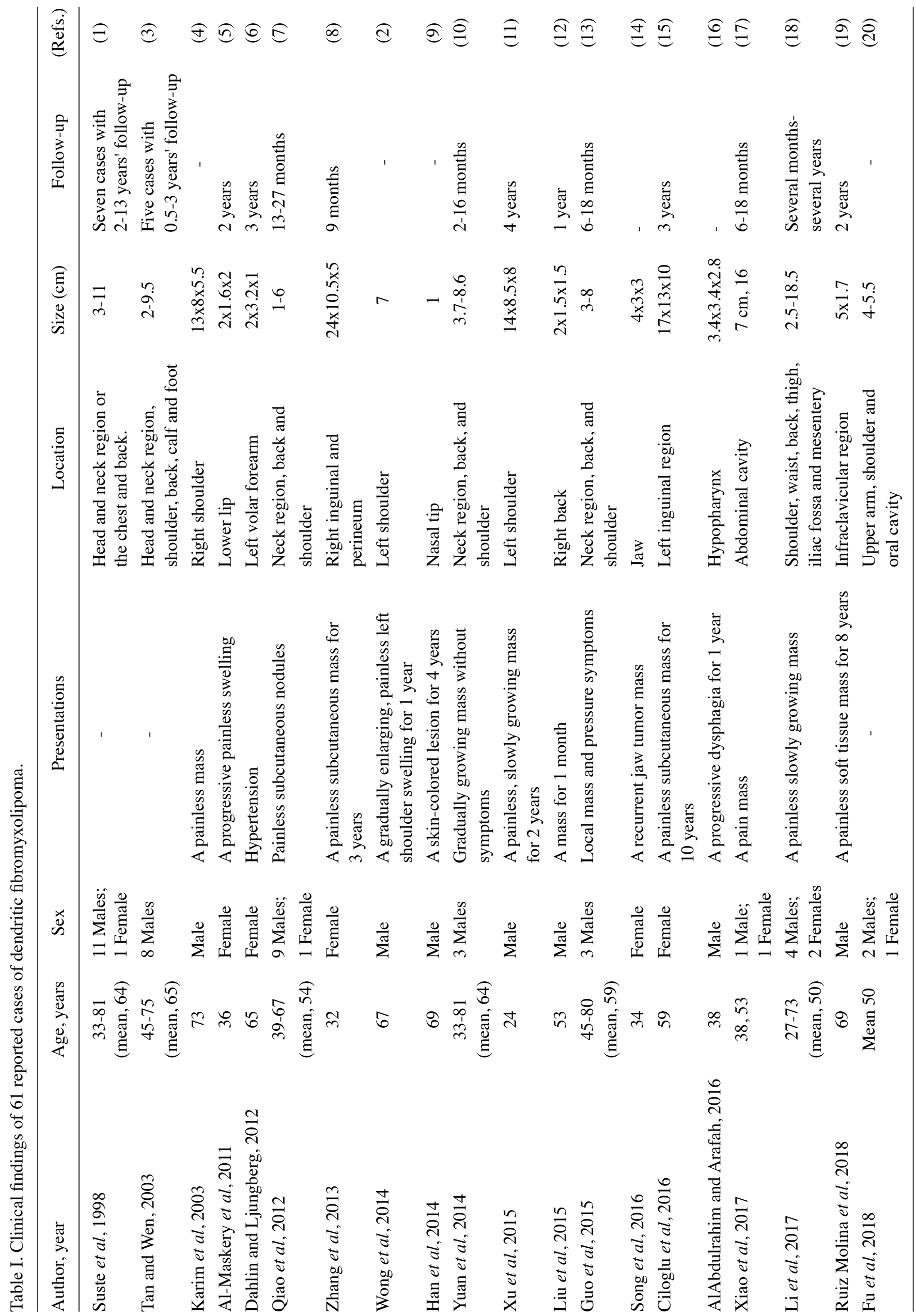


positive for CD34, vimentin and BCL-2. However, BCL-2 was not invariably positive in the present three cases, which had also been observed for two previous cases $(6,11)$.

The tumor may be confused with other myxoid mesenchymal tumors. i) MLS and DFML: they may share a distinct myxoid background and mature adipocytes. They are easy to be confused, especially when the lesions occur in non-superficial sites (such as case 3). However, they can be distinguished from each other by histology, immunohistochemistry and molecular genetics $(3,21,22)$. DFML is mostly located in the superficial tissues. Morphologically, DFML consists of abundant delicate, arborizing blood vessels and bland spindle or stellate-shaped cells in a myxoid with a collagenous matrix. The adipocytes were scattered, and definite lipoblasts were not identified. The short spindle cells were sparse and lacked atypia and mitosis. Thus, it may be somewhat difficult to make a definite diagnosis. In contrast, MLS occurs mostly in the deep soft tissues of the lower extremities. The tumor is mainly composed of three components: Adipocytes with different degrees of differentiation, myxoid stroma, and plexiform capillaries. In immunohistochemistry, CD34, BCL-2, and vimentin were expressed in DFML, but S-100 and Desmin were negative, while in MLS, the opposite result was found. In molecular genetics, 13q14.3 deletion exists in DFML, while FUS-DDIT3 $(>90 \%)$ or EWSR1-DDIT3 (<5\%) gene fusion exists in MLS (23). In case 3, the FISH detection for FUS-DDIT3 was negative, and the immunohistochemistry for NY-ESO-1 (a specific immunomarker for MLS) was also negative. These results can rule out an MLS. Since 13q14.3 detection is an important biomarker for spindle cell lipoma (2), the lack of its detection is a limitation of this study. And the tissues obtained from the 3 patients were for the purposes of diagnosis only, not for testing novel biomarkers. The clinical history, histological morphology and immunohistochemistry were mainly used to identify these two diseases. ii) Myxofibrosarcoma (MFS) and DFML: in case 3, a possible diagnosis of MFS invading the pre-existing adipose tissues should be ruled out. The diagnosis of MFS mostly depends on the morphology, and immunohistochemistry may be not very helpful. MFS is a kind of malignant soft tissue tumor. The histologic features of MFS included the following: a commonly nodular growth pattern; a myxoid matrix containing elongated, curvilinear capillaries; and fusiform, round or stellate tumor cells with indistinct cell margins, slightly eosinophilic cytoplasm and hyperchromatic atypical nuclei. For the present case, it was well defined and had a clear boundary without involving the surrounding tissues. In addition, the adipocytes were evenly distributed and rather scattered. Thus, we believe the adipocytes were tumor components. Furthermore, the flow-up result also favors the diagnosis of a benign tumor. iii) Low-grade fibrous myxoid sarcoma (LGFMS) and DFML: The morphology of LGFMS is a vortex structure composed of fusiform fibroblast-like cells, and alternating collagen-like and myxoid regions are observed. In addition, arch vessels and perivascular hyalinosis can be seen. (4) Lipoblastoma and DFML: likewise, in addition to mucin-like interstitial and branched blood vessels, there are also fat vacuoles stellate and fusiform stromal cells. However, $90 \%$ of lipoblastomas occur in infants under three years of age, while DFML often occurs in middle-aged and older adults, and spindle cells are positive for CD34. (5) SFT: It can undergo extensive myxoid degeneration, and the spindle cells are positive for STAT-6, CD99, CD34 and BCL-2. However, the mature fat component is absent.

DFML is a special subtype of spindle cell lipoma. Complete resection is the best treatment choice. A diagnostic pitfall is other myxoid mesenchymal tumors, such as LMS and LGFMS, which may lead to 'overtreatment.' The postoperative recurrence and metastasis are rare after complete resection. Only one recurrent case was reported until now (14).

\section{Acknowledgements}

Not applicable.

\section{Funding}

No funding was received.

\section{Availability of data and materials}

The datasets used and/or data analyzed during the present study are available from the corresponding author on reasonable request.

\section{Authors' contributions}

HL, SH and HC conceived the present study. JW, QZ, XY and $\mathrm{HC}$ performed the experiments. HL, SH, JW, QZ and $\mathrm{XY}$ wrote the manuscript. XY and HC critically reviewed the manuscript. All authors read and approved the final version of the manuscript.

\section{Ethics approval and consent to participate}

The present study was approved by the Ethics Committee of the Qingdao Municipal Hospital (approval no. 2020-049). All patients provided their written informed consent.

\section{Patient consent for publication}

All patients provided their consent for the publication of their data and associated images.

\section{Competing interests}

The authors declare that they have no competing interests.

\section{References}

1. Suster S, Fisher C and Moran CA: Dendritic fibromyxolipoma: Clinicopathologic study of a distinctive benign soft tissue lesion that may be mistaken for a sarcoma. Ann Diagn Pathol 2: 111-120, 1998.

2. Wong YP, Chia WK, Low SF, Mohamed-Haflah NH and Sharifah NA: Dendritic fibromyxolipoma: A variant of spindle cell lipoma with extensive myxoid change, with cytogenetic evidence. Pathol Int 64: 346-351, 2014.

3. Tan GM and Wen P: Clinicopathologic features of dendritic fibromyxolipoma. Zhonghua Bing Li Xue Za Zhi 32: 404-408, 2003 (In Chinese).

4. Karim RZ, McCarthy SW, Palmer AA, Bonar SF and Scolyer RA: Intramuscular dendritic fibromyxolipoma: Myxoid variant of spindle cell lipoma? Pathol Int 53: 252-258, 2003. 
5. Al-Maskery AY, Al-Sidairy SM and Al-Hamadani AS Dendritic myxofibrolipoma: Often misdiagnosed as sarcoma. Craniomaxillofac Trauma Reconstr 4: 171-174, 2011.

6. Dahlin LB and Ljungberg O: Dendritic fibromyxolipoma adherent to the median nerve in the forearm. J Plast Surg Hand Surg 46: 120-123, 2012.

7. Qiao HG, Zhang C, Zhuang YL and Wang J: Dendritic fibromyxolipoma: A clinicopathological analysis of 10 cases. J Clin Exp Pathol 28: 1332-1335, 2012.

8. Zhang XJ, Zhou S, Nie K, Chen DF, Kui GJ and Zhang XH: Dendritic fibromyxolipoma in the right inguinal and perineum regions: A case report and review of the literature. Diagn Pathol 8: 157, 2013.

9. Han XC, Zheng LQ and Shang XL: Dendritic fibromyxolipoma on the nasal tip in an old patient. Int J Clin Exp Pathol 7: 7064-7067, 2014.

10. Yuan XX, Yuan JP, Yang YH, Yin YB and Luo B: Clillicopathological characteristics of dendritic fibromyxolipoma in muscle: An anaIysis of 3 cases. J Diagn Pathol 21: 1, 2014.

11. Xu X, Xiong W, Zheng L and Yu J: Intramuscular dendritic fibromyxolipoma in a 24-year-old male: A case report and review of the literature. Oncol Lett 9: 583-586, 2015.

12. Liu S, Wang X, Lei B, Ma H, Li J, Guo D and Xu S: Dendritic fibromyxolipoma in the latissimus dorsi: A case report and review of the literature. Int J Clin Exp Pathol 8: 8650-8654, 2015

13. Guo WW, Huang WQ, Kong QN and Han ZL: Clinicopathologic analysis of dendritic fibromyxolipoma. J Clin Pathol Res 35: 622-626, 2015

14. Song L, Wang Z, Xu JW and Qin YJ: Dendritic fibromyxolipoma of jaw: Report of a case. Zhonghua Bing Li Xue Za Zhi 45 276-277, 2016 (In Chinese).

15. Ciloglu S, Duran A, Keskin E and Yigit A: Dendritic fibromyxolipoma of left inguinal region. Indian J Pathol Microbiol 59: 250-251, 2016
16. AlAbdulsalam A and Arafah M: Dendritic fibromyxolipoma of the pyriform sinus: A case report and review of the literature. Case Rep Pathol 2016: 7289017, 2016.

17. Xiao XW, Zhang LF, Li WS and Liu Y: Clinicopathological characteristics of dendritic fibromyxolipoma in abdominal cavity: An analysis of two cases. Diagn Pathol 24: 7, 2017.

18. Li YQ, Ma Q, Chen Y, Tang Y and Qian ZH: Dendritic fibromyxolipoma: A clinicopathologic analysis of 6 cases and review of the literature. J Clin Pathol Res 37: 527-530, 2017.

19. Ruiz Molina I, Solis Garcia E and Civico Amat V: Dendritic infraclavicular fibromyxolipoma: At the boundary between spindle cell lipoma and solitary fibrous tumour. Rev Esp Patol 51: 44-48, 2018 (In Spanish).

20. Fu WL, Tang XF and Guo QN: A Clinicopathologic study of dendritic fibromyxolipoma. Med J West China 30: 503-506, 2018.

21. Abaricia $S$ and Hirbe AC: Diagnosis and treatment of myxoid liposarcomas: Histology matters. Curr Treat Options Oncol 19: 64, 2018.

22. Hei SM, Wei HJ, Chen H and Wang JG: Pathological significance of NY-ESO-1 expression in the diagnosis of myxoid liposarcoma. Zhonghua Bing Li Xue Za Zhi 48: 225-230, 2019 (In Chinese).

23. Yu JS, Colborne S, Hughes CS, Morin GB and Nielsen TO: The FUS-DDIT3 interactome in myxoid liposarcoma. Neoplasia 21: 740-751, 2019.

This work is licensed under a Creative Commons Attribution-NonCommercial-NoDerivatives 4.0 International (CC BY-NC-ND 4.0) License. 